\title{
The role of aflibercept in the management of diabetic macular edema
}

\author{
This article was published in the following Dove Press journal: \\ Drug Design, Development and Therapy \\ 6 August 2015 \\ Number of times this article has been viewed
}

\author{
Andrew A Chang ${ }^{1-3}$ \\ Thomas Hong ${ }^{1,2}$ \\ Shaun Y Ewe $e^{1,2}$ \\ Bobak Bahrami ${ }^{1,2}$ \\ Geoffrey K Broadhead ${ }^{1-3}$ \\ 'Sydney Institute of Vision Science, \\ ${ }^{2}$ Sydney Retina Clinic and Day Surgery, \\ ${ }^{3}$ Save Sight Institute, University of \\ Sydney, Sydney, NSW, Australia
}

\begin{abstract}
Diabetic macular edema (DME) represents one of the leading causes of visual impairment in working-age adults. Although there are several proven treatments available for this condition, pharmacotherapy through the use of intravitreal antivascular endothelial growth factor agents has revolutionized the management of DME over the past decade with superior outcomes compared to laser therapy. This review summarizes the pathophysiology and available treatment options for the management of DME, with an emphasis on the efficacy and safety profile of a single particular intravitreal antivascular endothelial growth factor agent, aflibercept.
\end{abstract}

Keywords: diabetic macular edema, aflibercept

\section{Introduction}

Diabetic retinopathy is a common microvascular complication of diabetes mellitus, occurring in nearly all type 1 diabetics and $80 \%$ of type 2 diabetics after a period of 20 years. ${ }^{1}$ The major cause of visual loss in these patients and one of the most common in working-aged adults is diabetic macular edema (DME). ${ }^{2}$

The pathogenesis of DME is multifactorial and is thought to result from a breakdown of the blood-retinal barrier with the leakage of plasma from macular blood vessels with resultant hard exudates and subsequent thickening of the retina. ${ }^{3}$ Our improved understanding of the pathogenesis and experience in the treatment of DME has led to the establishment of intravitreal anti-vascular endothelial growth factor (anti-VEGF) therapy as the preferred first line for the management of this condition over other therapies, including laser photocoagulation, steroids, and vitreoretinal surgery. ${ }^{4}$

There are several drugs blocking the VEGF pathway through different mechanisms, which have been shown to be effective in the management of DME (Table 1). Aflibercept is notable among these leading to improved anatomical and visual outcomes in those presenting with a poorer visual acuity. ${ }^{5}$

\section{Pathogenesis}

The key etiologic factor for the development of DME is hyperglycemia. This is hypothesized to lead to retinopathy through activating one or more biochemical pathways, including increased flux through the polyol pathway, ${ }^{6}$ production of advanced glycation end products, ${ }^{7}$ protein kinase $\mathrm{C},{ }^{8}$ and the hexosamine pathway. ${ }^{9}$ The end result of these biochemical pathways is oxidative stress, inflammation, and vascular dysfunction. This leads to upregulation of growth factors and cytokines, including VEGF, disrupting the blood-retinal barrier, and resulting in tissue edema. ${ }^{10}$
Correspondence: Andrew Chang Sydney Retina Clinic and Day Surgery, Level I3, Park House, I 87 Macquarie Street, Sydney, NSW 2000, Australia Tel +6I 2 922। 3755

Fax +6I 292211637

Email achang@sydneyretina.com.au 
Table I Available anti-VEGF agents, mechanisms and indications

\begin{tabular}{|c|c|c|c|}
\hline Anti-VEGF agent & Type & Mechanism & US FDA-approved indication \\
\hline $\begin{array}{l}\text { Pegaptanib } \\
\text { Macugen, Eyetech Pharmaceuticals, } \\
\text { Melville, NY/Pfizer, New York, NY }{ }^{61}\end{array}$ & Pegylated anti-VEGF aptamer & $\begin{array}{l}\text { Competitively binds to } \\
\text { the VEGF-AI } 65 \text { isoform } \\
\text { at the heparin binding site }\end{array}$ & nAMD \\
\hline $\begin{array}{l}\text { Bevacizumab } \\
\text { Avastin, Genetech, San Francisco, } \mathrm{CA}^{62}\end{array}$ & $\begin{array}{l}\text { Recombinant humanized monoclonal } \\
\text { antibody }\end{array}$ & $\begin{array}{l}\text { Binds to the receptor } \\
\text { binding site for all } \\
\text { isoforms of VEGF-A }\end{array}$ & $\begin{array}{l}\text { Glioblastoma, metastatic colorectal } \\
\text { cancer, non-small-cell lung cancer, } \\
\text { metastatic kidney cancer; nAMD }\end{array}$ \\
\hline $\begin{array}{l}\text { Ranibizumab } \\
\text { Lucentis, Genetech, San Francisco, } \mathrm{CA}^{63}\end{array}$ & $\begin{array}{l}\text { Recombinant, humanized monoclonal } \\
\text { antigen-binding fragment }\end{array}$ & $\begin{array}{l}\text { Neutralizes all forms of } \\
\text { VEGF-A }\end{array}$ & $\begin{array}{l}\text { nAMD, macular edema following } \\
\text { RVO, DME }\end{array}$ \\
\hline $\begin{array}{l}\text { Aflibercept } \\
\text { Eylea, Regeneron Pharmaceuticals, Inc., } \\
\text { Tarrytown, New York, NY53 }\end{array}$ & $\begin{array}{l}\text { Human recombinant fusion protein; } \\
\text { combination of the second Ig } \\
\text { domain of VEGFR-I and third Ig } \\
\text { binding domain of VEGFR- } 2 \text { with the } \\
\text { constant Fc portion of the } \operatorname{lgG} \text { I }\end{array}$ & $\begin{array}{l}\text { Soluble decoy receptor } \\
\text { with high affinity for } \\
\text { binding to VEGF } \\
\text { molecules VEGF-A and } \\
\text { PIGF }\end{array}$ & $\begin{array}{l}\text { nAMD, macular edema following } \\
\text { RVO, DME }\end{array}$ \\
\hline
\end{tabular}

Abbreviations: VEGF, antivascular endothelial growth factor; nAMD, neovascular age-related macular degeneration; RVO, retina vein occlusion; DME, diabetic macular edema; PIGF, placenta growth factor.

\section{DME treatment options}

\section{Laser therapy}

In 1985, the Early Treatment of Diabetic Retinopathy Study (ETDRS) demonstrated that focal laser photocoagulation in DME reduced the risk of visual loss of 15 or more letters by half at 1 year. ${ }^{11}$ This finding established laser therapy as a standard of care for DME. The proposed mechanism for the efficacy of this therapy is decreased production of cytokines, predominantly VEGF, ${ }^{12-14}$ and alteration in barrier properties of the retinal pigment epithelium, resulting in an increase of the active reabsorptive transport of fluids from the retina to the intravascular space. ${ }^{15}$

\section{Intravitreal steroids}

Despite the benefit of laser treatment in helping to prevent the progression of DME, there remained a significant subgroup of the EDTRS participants who lost 15 or more letters at the conclusion of the study. ${ }^{11}$ Given experimental animal data suggesting steroid medication may stabilize the blood-retinal barrier, ${ }^{16}$ subsequent trials were conducted demonstrating the benefits in preserving visual acuity and reducing central macular thickness with injections of intravitreal steroids. ${ }^{17}$ This supports the role of inflammation and inflammatory cytokines in the pathogenesis of DME. Further studies have demonstrated the effects of intravitreal steroids in the inhibition of blood-retinal barrier breakdown with the prevention of leukostasis, through downregulation of angiogenic VEGF (and its receptors) ${ }^{18}$ and inflammatory cytokines, including interleukin-6, interleukin-8, interferoninduced protein-10, monocyte chemotactic protein-1, platelet-derived growth factor-AA, and intercellular adhesion molecule-1. ${ }^{19-21}$
However, intravitreal corticosteroid therapy has a notable adverse event profile, including elevation of intraocular pressure and cataract development, which may threaten the desired visual outcomes. ${ }^{17,22}$ Importantly, when the effect of cataract is accounted for, visual acuity outcomes for pseudophakic eyes treated with triamcinolone may be comparable to eyes treated with anti-VEGF drugs. ${ }^{23}$ Careful patient selection for these therapies is important and relevant.

\section{Other treatment modalities}

Therapies targeted at other cytokines have been investigated in preclinical and clinical trials, including inhibitors of multiple growth factors, nonsteroidal anti-inflammatory drugs, targeted chemokine, and cytokine inhibitors. ${ }^{24-28}$ Though some of these therapies have shown promise in early testing as primary or adjunctive therapy, further investigation and comparison with current treatments is required.

\section{Anti-VEGF therapy}

The discovery of elevated VEGF levels in angiogenic diseases such as metastatic cancer, neovascular age-related macular degeneration (nAMD), ${ }^{29}$ branch and central retinal vein occlusion (RVO), ${ }^{30,31}$ and $\mathrm{DME}^{32,33}$ led to the revolutionary development and the use of anti-VEGF therapies in these pathologies. In recent years, the expanding use of anti-VEGF agents for the treatment of angiogenic retinal diseases such as DME, nAMD, and RVO has resulted in improved outcomes compared to previously used treatment options. ${ }^{34-37}$

\section{The role of VEGF}

VEGF is a protein, which plays a major role in the regulation of angiogenesis. There are five types of VEGF that have 
been identified in humans; these include VEGF-A, VEGF-B, VEGF-C, VEGF-D, and placenta growth factor (PIGF), with VEGF-A strongly implicated in ocular angiogenic diseases. ${ }^{38}$ It binds to and results in the activation of two tyrosine kinase receptors: VEGF receptor (VEGFR)-1, which plays a key role in conditions such as inflammation, ischemia, and cancer, and VEGFR-2, by mediating endothelial growth and survival signals. ${ }^{39}$

In vitro studies have demonstrated increased retinal endothelial cell permeability, proliferation, cell survival, and migration due to exposure to VEGF-A. ${ }^{40,41}$ However, stimulation of endothelial cell permeability and the modulation of VEGF-A function were not shown with PlGF or VEGF-B. ${ }^{42-45}$

Research from animal models studies suggests that PlGF may play a critical role in the development of diabetic retinopathy. ${ }^{46}$ Genetic deletion of PlGF in a diabetic mouse strain demonstrated protection of retinal damage through prevention of diabetes-induced retinal cell death, capillary degeneration, pericyte loss, and blood-retinal barrier breakdown. ${ }^{46}$

\section{VEGF pathway activation and inhibition}

The VEGF pathway is activated when VEGF binds to VEGFR-1 and VEGFR-2 on endothelial cells. VEGFR-1 is a $180 \mathrm{kDa}$ high-affinity receptor of VEGF-A, VEGF-B, and $\mathrm{PlGF}{ }^{45}$ whereas VEGFR-2 is a $200-230 \mathrm{kDa}$ high-affinity receptor for VEGF-A. ${ }^{45}$ Laboratory techniques such as alternative mRNA splicing have produced up to nine further isoforms of VEGF-A. ${ }^{45}$ The smaller VEGF-A isoforms $\left(\mathrm{VEGF}_{121}\right.$ and $\left.\mathrm{VEGF}_{165}\right)$ are secreted and are freely diffusible, whereas the larger isoforms $\left(\mathrm{VEGF}_{189}\right.$ and $\left.\mathrm{VEGF}_{206}\right)$ are bound to heparin-containing proteoglycans of the basement membrane. .77,48 $^{2}$

Inhibition of the VEGF pathway is achieved by blocking antibodies targeting VEGF ${ }^{49-51}$ or its receptors. ${ }^{52,53}$ Another approach is to use soluble decoy receptors to prevent VEGF binding to its receptors; the mechanism of action by which aflibercept functions.

\section{VEGF in retinal disease}

Excessive activation of VEGF occurs in angiogenic retinal diseases, leading to proliferation and inflammation of vascular endothelial cells, margination of leukocytes, and vascular permeability with subsequent vascular leakage. ${ }^{45}$ Similarly, intravitreal injection of VEGF in primate experiments resulted in findings resembling diabetic retinopathy, including macular edema and retinal neovascularization. ${ }^{54-56}$ Hypoxia is a major regulator of VEGF-A expression, ${ }^{13,47}$ distinguishing VEGF-A from other growth factors postulated to play a role in ocular neovascular diseases (such as insulin-like growth factor-1, fibroblast growth factors, epidermal growth factor, PlGF, and VEGF-B). ${ }^{57}$ Other stimuli contributing to VEGF expression include estrogen, thyroidstimulating hormone, transformation, p53 mutation, tumor promoters, and nitric oxide. ${ }^{45}$

These findings led to the development and use of antiVEGF agents to treat and inhibit aberrant angiogenesis in retinal diseases such as DME and nAMD. Unlike laser therapy, which was previously a mainstay of therapy for these disorders, intravitreal anti-VEGF therapy has been shown to be effective in not only reducing the risk of visual loss, but also in improving vision among patients with nAMD, RVO, and DME. ${ }^{36,37,58-60}$

\section{Anti-VEGF agents}

There are several available anti-VEGF therapies for ophthalmic diseases, including pegaptanib ${ }^{61}$ bevacizumab, ${ }^{62}$ ranibizumab, ${ }^{63}$ and aflibercept..$^{53}$ These are summarized in Table 1.

\section{Aflibercept}

Aflibercept (Eylea, Regeneron Pharmaceuticals, Inc., Tarrytown, New York, NY) ${ }^{64}$ is a $115 \mathrm{kDa}$ recombinant fusion protein produced from hamster ovary cells and is composed of the combination of a fusion of the second Ig domain of human VEGFR-1 and the third Ig binding domain of human VEGFR-2 with the constant fragment crystallizable portion of the human $\operatorname{IgG} 1 .{ }^{53}$ It is US FDA approved for the treatment of nAMD, central RVO, and DME.

\section{Mechanism of action}

Aflibercept was engineered to act as a soluble decoy receptor with high affinity for binding to all isoforms of VEGF-A, VEGF-B, and PIGF molecules. ${ }^{53}$ This blocks VEGF pathway activation by inhibiting the binding and activation of the cognate VEGFRs, preventing the undesirable effects of VEGF-A such as neovascularization and increased vascular permeability. Additionally, given the implication of PlGF in the pathogenesis of diabetic retinopathy, blockade of this may also account for potential benefits in the use of aflibercept compared with other anti-VEGF agents. ${ }^{46}$

Similar to other anti-VEGF agents, aflibercept contains an $\mathrm{Fc}$ domain as part of its structure. However, it forms stable, inert 1:1 homogeneous complexes with VEGF, 
unlike antibodies like bevacizumab, which form heterogeneous multimeric immune complexes. ${ }^{65}$ Such multimeric immune complexes are rapidly cleared from the systemic circulation and can deposit in tissues, causing undesirable off-mechanism effects, such as the platelet aggregation seen in bevacizumab. ${ }^{66}$ These complexes have been postulated to be a possible mechanism for arterial thromboembolic events seen in clinical trials involving bevacizumab ${ }^{65,66}$ and may also cause renal damage when complexes accumulate in the kidney glomeruli. By remaining in the systemic circulation, aflibercept does not appear to induce platelet aggregation or deposit in tissues, providing a theoretical safety benefit compared with bevacizumab.

However, increased risk of thromboembolic events has also been reported in trials of other anti-VEGF agents using ranibizumab, yet it does not form complexes, suggesting other factors may be involved. ${ }^{67}$ Given the role of VEGF in endothelial cell proliferation and survival, one suggestion is that by blocking this effect there is exposure of subendothelial collagen resulting in activation of prothrombotic pathways. ${ }^{65,68,69}$

\section{Pharmacokinetics}

The systemic pharmacokinetics of intravitreal aflibercept (2.0 $\mathrm{mg}$ ) have been compared to that of ranibizumab $(0.5 \mathrm{mg})$ and bevacizumab $(1.25 \mathrm{mg})$ in a study of 56 patients with nAMD. ${ }^{70}$ This study revealed that systemic exposure to aflibercept was higher than that of ranibizumab, with maximum serum concentration five and sevenfold greater after the first dose and third doses respectively and minimum serum concentration 37- and 53-fold greater after the first and third doses, respectively. This pharmacokinetic study also demonstrated there was accumulation of both aflibercept and bevacizumab after three intravitreal injections but not ranibizumab. Aflibercept was also the most potent of these three drugs in reducing plasma-free VEGF with levels undetectable from 3 hours postdose to greater than 1 week postdose. ${ }^{71}$ It is postulated that the Fc fragment present in both the bevacizumab and aflibercept molecules extends their serum half-life, accounting for these differences. ${ }^{72}$ The clinical significance of this is, however, yet to be elucidated.

Drug clearance from the vitreous of the eye occurs across the retina through the choroidal circulation and through diffusion into the anterior chamber to exit via the trabecular meshwork. ${ }^{73}$ There are no published reports about the intravitreal half-life of aflibercept in humans; however, there have been two rabbit models estimating this through immunoassay and radioisotope imaging techniques as between 4.5 days and 4.58 days. ${ }^{74}$ Given the anatomic and biological differences between humans and rabbits, the half-life is expected to be longer in humans, suggested to be 9 days based on its intermediate molecular size between ranibizumab and bevacizumab. ${ }^{73}$ Further mathematical modeling suggests that aflibercept is able to maintain significant intraocular binding activity up to 10-12 weeks after a single injection. ${ }^{73}$

\section{Aflibercept in clinical trials of DME}

Following the results of a Phase I trial assessing the safety and the bioactivity of aflibercept in DME, Phase II (DA VINCI $^{75}$ ), and Phase III (VISTA, VIVID ${ }^{76}$, and Protocol $\mathrm{T}^{5}$ ) studies have confirmed its efficacy and safety for this indication (Table 2).

DA VINCI (DME and VEGF Trap-Eye: INvestigation of Clinical Impact $)^{75}$ was a 52-week, multicenter, randomized, double-masked, active-controlled Phase II clinical trial that assessed the safety and efficacy of intravitreal aflibercept in comparison with focal/grid laser photocoagulation in patients with DME. Two hundred and twenty-one patients were randomly assigned to either $0.5 \mathrm{mg}$ aflibercept every 4 weeks (0.5q4), $2 \mathrm{mg}$ aflibercept every 4 weeks (2q4), $2 \mathrm{mg}$ aflibercept for three initial monthly doses and then every 8 weeks (2q8), $2 \mathrm{mg}$ aflibercept for three initial monthly doses and then on an as-needed basis (2PRN), or macular laser photocoagulation as specified by the modified ETDRS protocol.

VISTA (Study of Intravitreal Administration of VEGF Trap-Eye in Patients with DME) and VIVID ${ }^{76}$ (VEGF Trap-Eye in vision impairment due to DME) were two multicenter, randomized, double-masked, active-controlled Phase III trials of 872 eyes with center-involving DME. VISTA was conducted in the US only, whereas VIVID was conducted in Europe, Japan, and Australia. Eyes were randomized for treatment with intravitreal aflibercept injection either $2 \mathrm{mg}$ every 4 weeks (2q4), $2 \mathrm{mg}$ every 8 weeks after five initial monthly doses (2q8), or macular laser photocoagulation. ${ }^{76}$

The Protocol T Study ${ }^{5}$ was a 52 week, multicenter, randomized trial by the Diabetic Retinopathy Clinical Research Network comparing the efficacy and safety of intravitreal aflibercept (2 $\mathrm{mg})$, bevacizumab (1.25 $\mathrm{mg}$ ), and ranibizumab $(0.3 \mathrm{mg})$. Six hundred and sixty participants were randomized in a 1:1:1 fashion to each arm of treatment, which specified injections at baseline and every subsequent 4 weeks unless visual acuity was $20 / 20$ or better with a central macular 
Table 2 Summary of studies assessing the use of aflibercept in the treatment of diabetic macular edema

\begin{tabular}{|c|c|c|c|c|c|}
\hline Study & Study design & Year & $\begin{array}{l}\text { Sample size } \\
\text { (patients) }\end{array}$ & VA (letters) study eye & CMT $(\mu \mathrm{m})$ study eye \\
\hline Da Vinci (Phase II) ${ }^{75}$ & $\begin{array}{l}\text { Multicenter, randomized, double } \\
\text { masked, active controlled }\end{array}$ & 2012 & & & \\
\hline $0.5 q 4$ & & & 44 & $11.0^{\mathrm{a}}$ & $-165.4^{\mathrm{a}}$ \\
\hline $2 q 4$ & & & 44 & $13.1^{\mathrm{a}}$ & $-227.4^{\mathrm{a}}$ \\
\hline $2 q 8$ & & & 42 & $9.7^{\mathrm{a}}$ & $-187.8^{a}$ \\
\hline $2 \mathrm{PRN}$ & & & 45 & $12.0^{\mathrm{a}}$ & $-180.3^{a}$ \\
\hline Control $^{b}$ & & & 44 & 2.5 & -58.4 \\
\hline VISTA (Phase III) ${ }^{76}$ & $\begin{array}{l}\text { Multicenter, randomized, double } \\
\text { masked, active controlled }\end{array}$ & 2014 & & & \\
\hline $2 q 4$ & & & 154 & $12.5 \pm 9.5^{\mathrm{a}}$ & $-185.9 \pm 150.7^{a}$ \\
\hline $2 q 8$ & & & $15 \mid$ & $10.7 \pm 8.2^{\mathrm{a}}$ & $-183.1 \pm 153.5^{\mathrm{a}}$ \\
\hline Control $^{\mathrm{b}}$ & & & 154 & $0.2 \pm 12.5$ & $-73.3 \pm 176.7$ \\
\hline VIVID (Phase III) ${ }^{76}$ & $\begin{array}{l}\text { Multicenter, randomized, double } \\
\text { masked, active controlled }\end{array}$ & 2014 & & & \\
\hline $2 q 4$ & & & 136 & $10.5 \pm 9.5^{\mathrm{a}}$ & $-195.0 \pm 146.6^{a}$ \\
\hline $2 q 8$ & & & 135 & $10.7 \pm 9.3^{\mathrm{a}}$ & $-192.4 \pm 149.9^{a}$ \\
\hline Control $^{b}$ & & & 132 & $1.2 \pm 10.6$ & $-66.2 \pm 139.0$ \\
\hline Protocol T (Phase III) ${ }^{5}$ & $\begin{array}{l}\text { Multicenter, randomized, single } \\
\text { masked (subject) }\end{array}$ & 2015 & & & \\
\hline $2 q 4$ & & & 224 & 13.3 & $-169 \pm 138$ \\
\hline Bevacizumab & & & 218 & 9.7 & $-101 \pm|2|$ \\
\hline Ranibizumab (0.3 mg) & & & 218 & 11.2 & $-147 \pm 134$ \\
\hline
\end{tabular}

Notes: ${ }^{a} p<0.05$ compared to control arm; ${ }^{b}$ macular laser photocoagulation; $0.5 q 4-0.5 \mathrm{mg}$ aflibercept; every 4 weeks; $2 q 4-2 \mathrm{mg}$ aflibercept every 4 weeks; $2 q 8-2 \mathrm{mg}$ aflibercept every 8 weeks following three loading doses; PRN - aflibercept pro re nata following three loading doses.

Abbreviations: VA, visual acuity; CMT, central macular thickness.

thickness below eligibility threshold and no improvement or worsening in the visual acuity in response to the previous two injections.

All three of these studies demonstrated benefits in the improvement of visual acuity and reduction of central macular thickness from baseline with the aflibercept arms as shown in Table 2. Both DA VINCI and VIVID/VISTA demonstrated superiority to laser photocoagulation and also improvements in the diabetic retinopathy severity score in those participants. DA VINCI demonstrated similar anatomical and visual outcomes in the four treatment arms of aflibercept, despite the differences in dosing.

Protocol T demonstrated that head-to-head there was no clinically meaningful difference between the three antiVEGF agents in terms of improvement of best-corrected visual acuity. However, when the participants were stratified into their presenting visual acuity, aflibercept resulted in improved visual outcomes compared with both ranibizumab and bevacizumab when the presenting visual acuity was $<69$ letters $(\sim<20 / 50)$. When the presenting visual acuity loss was only mild (between 78 and 69 letters), no apparent differences in mean visual improvement were found. Additionally, reductions in central macular thickness were significantly more marked with aflibercept compared to both ranibizumab and bevacizumab.

None of these three trials had sufficiently large cohorts to determine definitive statements regarding the systemic safety of aflibercept. Both DA VINCI and VISTA/VIVID demonstrated a similar ocular adverse event profile for aflibercept compared to laser photocoagulation. There were no differences in ocular adverse events between the three treatment arms in Protocol T; however, a post hoc analysis performed demonstrated a statistically significant increased frequency in cardiac and vascular disorders in the ranibizumab group.

There are some limitations with the design of the clinical trials. In VIVID/VISTA, the exclusion criteria included uncontrolled diabetes mellitus defined as $\mathrm{HbA}_{1 \mathrm{C}}>12 \%$ in VIVID or at the discretion of the investigator in VISTA contributing to a potential selection bias in these cases. Additionally, a second source of selection bias was the exclusion criteria of more than two previous macular laser treatments in the study eye or if in the opinion of the investigator that the patient had no potential to benefit from laser treatment.

In Protocol T, the dose of ranibizumab utilized was $0.3 \mathrm{mg}$, and a potential issue is raised regarding whether using a $0.5 \mathrm{mg}$ dose would have had a different outcome in 
this treatment arm. Previous studies evaluating ranibizumab for DME demonstrated that there was no difference in terms of efficacy between these dosages; however, smaller studies have demonstrated some benefit with higher dosages of ranibizumab for refractory DME. ${ }^{77}$

Additionally, the bevacizumab used in this study was repackaged into single use vials at a central pharmacy, perhaps not reflecting clinical practice whereby these are sourced from various compounding pharmacies. Bevacizumab from the same compounding pharmacy has been shown to have varying protein concentrations raising the suspicion of uniformity amongst the potency of the drug being administered. ${ }^{78}$

\section{Future directions}

The clinical trials have shown aflibercept to be an effective treatment for DME. Due to small sample sizes, it is not possible to make definitive statements about the systemic safety of aflibercept. Further Phase IV studies, meta-analyses, and postmarketing surveillance will provide valuable data.

The role of aflibercept in managing DME refractory to the treatment with other intravitreal agents is a relevant clinical question in this subgroup of patients. Although the pathologies are very distinct, studies in $n \mathrm{AMD}^{79,80}$ have shown visual and anatomical benefit in switching from between anti-VEGF agents. The intense regime of rigorous clinical review and treatment with anti-VEGF while yielding excellent visual outcomes will be burdensome for the patient, clinics, and treating physicians. It is likely that alternative treatment paradigms including "treat and extend" will be explored in an attempt to reduce this treatment burden.

\section{Conclusion}

Previous treatment strategies for DME such as steroid and laser photocoagulation have been shown to effectively preserve the vision. The effectiveness of anti-VEGF therapy to improve the vision in patients with DME is clearly established. Aflibercept in recent trials suggests superior visual outcomes in eyes with worse initial vision. The higher binding affinity to VEGF and additional action of PlGF of aflibercept may explain this difference in efficacy. With continuing experience of this important therapy, clinicians will explore alternative treatment algorithms to modify the injection frequency and treatment burden while maintaining effectiveness and safety in managing their diabetic patients.

\section{Disclosure}

Andrew A Chang is a consultant for Bayer, Novartis and Alcon. The authors report no conflicts of interest in this work.

\section{References}

1. Klein R, Klein BE, Moss SE, Davis MD, DeMets DL. The Wisconsin epidemiologic study of diabetic retinopathy. III. Prevalence and risk of diabetic retinopathy when age at diagnosis is 30 or more years. Arch Ophthalmol. 1984;102:527-532.

2. Liew G, Michaelides M, Bunce C. A comparison of the causes of blindness certifications in England and Wales in working age adults (16-64 years), 1999-2000 with 2009-2010. BMJ Open. 2014;4: e004015.

3. Antcliff RJ, Marshall J. The pathogenesis of edema in diabetic maculopathy. Semin Ophthalmol. 1999;14:223-232.

4. Virgili G, Parravano M, Menchini F, Evans JR. Anti-vascular endothelial growth factor for diabetic macular oedema. Cochrane Database Syst Rev. 2014;10:CD007419.

5. Wells JA, Glassman AR, Ayala AR, et al. Aflibercept, bevacizumab, or ranibizumab for diabetic macular edema. N Engl J Med. 2015;372: $1193-1203$.

6. Lorenzi M. The polyol pathway as a mechanism for diabetic retinopathy: attractive, elusive, and resilient. Exp Diabetes Res. 2007;2007: 61038.

7. Goh SY, Cooper ME. Clinical review: the role of advanced glycation end products in progression and complications of diabetes. J Clin Endocrinol Metab. 2008;93:1143-1152.

8. Geraldes P, King GL. Activation of protein kinase $\mathrm{C}$ isoforms and its impact on diabetic complications. Circ Res. 2010;106:1319-1331.

9. Nakamura M, Barber AJ, Antonetti DA, et al. Excessive hexosamines block the neuroprotective effect of insulin and induce apoptosis in retinal neurons. J Biol Chem. 2001;276:43748-43755.

10. Brownlee M. The pathobiology of diabetic complications: a unifying mechanism. Diabetes. 2005;54:1615-1625.

11. Photocoagulation for diabetic macular edema. Early Treatment Diabetic Retinopathy Study report number 1. Early Treatment Diabetic Retinopathy Study Research Group. Arch Ophthalmol. 1985;103: 1796-1806.

12. Lip PL, Belgore F, Blann AD, Hope-Ross MW, Gibson JM, Lip GY. Plasma VEGF and soluble VEGF receptor FLT-1 in proliferative retinopathy: relationship to endothelial dysfunction and laser treatment. Invest Ophthalmol Vis Sci. 2000;41:2115-2119.

13. Stefansson E. The therapeutic effects of retinal laser treatment and vitrectomy. A theory based on oxygen and vascular physiology. Acta Ophthalmol Scand. 2001;79:435-440.

14. Miura Y, Klettner A, Roider J. VEGF antagonists decrease barrier function of retinal pigment epithelium in vitro: possible participation of intracellular glutathione. Invest Ophthalmol Vis Sci. 2010;51:4848-4855.

15. Sander B, Larsen M, Engler C, Moldow B, Lund-Andersen H. Diabetic macular oedema: the effect of photocoagulation on fluorescein transport across the blood-retinal barrier. Br J Ophthalmol. 2002;86: 1139-1142.

16. Wilson CA, Berkowitz BA, Sato Y, Ando N, Handa JT, de Juan E Jr. Treatment with intravitreal steroid reduces blood-retinal barrier breakdown due to retinal photocoagulation. Arch Ophthalmol. 1992;110: $1155-1159$.

17. Audren F, Erginay A, Haouchine B, et al. Intravitreal triamcinolone acetonide for diffuse diabetic macular oedema: 6-month results of a prospective controlled trial. Acta Ophthalmol Scand. 2006;84:624-630.

18. Zhang X, Bao S, Lai D, Rapkins RW, Gillies MC. Intravitreal triamcinolone acetonide inhibits breakdown of the blood-retinal barrier through differential regulation of VEGF-A and its receptors in early diabetic rat retinas. Diabetes. 2008;57:1026-1033.

19. Sohn HJ, Han DH, Kim IT, et al. Changes in aqueous concentrations of various cytokines after intravitreal triamcinolone versus bevacizumab for diabetic macular edema. Am J Ophthalmol. 2011;152:686-694.

20. Wang K, Wang Y, Gao L, Li X, Li M, Guo J. Dexamethasone inhibits leukocyte accumulation and vascular permeability in retina of streptozotocin-induced diabetic rats via reducing vascular endothelial growth factor and intercellular adhesion molecule-1 expression. Biol Pharm Bull. 2008;31:1541-1546. 
21. Tamura H, Miyamoto K, Kiryu J, et al. Intravitreal injection of corticosteroid attenuates leukostasis and vascular leakage in experimental diabetic retina. Invest Ophthalmol Vis Sci. 2005;46:1440-1444.

22. Massin P, Audren F, Haouchine B, et al. Intravitreal triamcinolone acetonide for diabetic diffuse macular edema: preliminary results of a prospective controlled trial. Ophthalmology. 2004;111:218-224.

23. Diabetic Retinopathy Clinical Research Network, Elman MJ, Aiello LP, et al. Randomized trial evaluating ranibizumab plus prompt or deferred laser or triamcinolone plus prompt laser for diabetic macular edema Ophthalmology. 2010;117:1064-1077.

24. Campochiaro PA, Channa R, Berger BB, et al. Treatment of diabetic macular edema with a designed ankyrin repeat protein that binds vascular endothelial growth factor: a phase I/II study. Am J Ophthalmol. 2013; 155(697-704):704.

25. Dugel PU, Blumenkranz MS, Haller JA, et al. A randomized, dose-escalation study of subconjunctival and intravitreal injections of sirolimus in patients with diabetic macular edema. Ophthalmology. 2012;119:124-131.

26. Nguyen QD, Schachar RA, Nduaka CI, et al. Dose-ranging evaluation of intravitreal siRNA PF-04523655 for diabetic macular edema (the DEGAS study). Invest Ophthalmol Vis Sci. 2012;53:7666-7674.

27. Friedman SM, Almukhtar TH, Baker CW, et al. Topical nepafenec in eyes with noncentral diabetic macular edema. Retina. 2015;35:944-956.

28. Sfikakis PP, Grigoropoulos V, Emfietzoglou I, et al. Theodossiadis, Infliximab for diabetic macular edema refractory to laser photocoagulation: a randomized, double-blind, placebo-controlled, crossover, 32-week study. Diabetes Care. 2010;33:1523-1528.

29. Tong JP, Chan WM, Liu DT, et al. Aqueous humor levels of vascular endothelial growth factor and pigment epithelium-derived factor in polypoidal choroidal vasculopathy and choroidal neovascularization. Am J Ophthalmol. 2006;141:456-462.

30. Noma H, Funatsu H, Mimura T, Eguchi S, Shimada K. Role of soluble vascular endothelial growth factor receptor-2 in macular oedema with central retinal vein occlusion. Br J Ophthalmol. 2011;95:788-792.

31. Campochiaro PA, Heier JS, Feiner L, et al. Ranibizumab for macular edema following branch retinal vein occlusion: six-month primary end point results of a phase III study. Ophthalmology. 2010;117: 1102-1112.

32. Funatsu H, Yamashita H, Noma H, Mimura T, Yamashita T, Hori S. Increased levels of vascular endothelial growth factor and interleukin-6 in the aqueous humor of diabetics with macular edema. Am J Ophthalmol. 2002;133:70-77.

33. Grant MB, Afzal A, Spoerri P, Pan H, Shaw LC, Mames RN. The role of growth factors in the pathogenesis of diabetic retinopathy. Expert Opin Investig Drugs. 2004;13:1275-1293.

34. Korobelnik JF, Holz FG, Roider J, et al. Intravitreal aflibercept injection for macular edema resulting from central retinal vein occlusion: one-year results of the phase 3 GALILEO Study. Ophthalmology. 2014; 121:202-208.

35. Heier JS, Clark WL, Boyer DS, et al. Intravitreal aflibercept injection for macular edema due to central retinal vein occlusion: two-year results from the COPERNICUS Study. Ophthalmology. 2014;121:1414-1420.

36. Virgili G, Parravano M, Menchini F, Brunetti M. Antiangiogenic therapy with anti-vascular endothelial growth factor modalities for diabetic macular oedema. Cochrane Database Syst Rev. 2012;12: CD007419.

37. Braithwaite T, Nanji AA, Lindsley K, Greenberg PB. Anti-vascular endothelial growth factor for macular oedema secondary to central retinal vein occlusion. Cochrane Database Syst Rev. 2014;5:CD007325.

38. Ferrara N, Gerber HP, LeCouter J. The biology of VEGF and its receptors. Nat Med. 2003;9:669-676.

39. Fong GH, Rossant J, Gertsenstein M, Breitman ML. Role of the Flt-1 receptor tyrosine kinase in regulating the assembly of vascular endothelium. Nature. 1995;376:66-70.

40. Leung DW, Cachianes G, Kuang WJ, Goeddel DV, Ferrara N. Vascular endothelial growth factor is a secreted angiogenic mitogen. Science. 1989; 246:1306-1309.
41. Connolly DT, Heuvelman DM, Nelson R, et al. Tumor vascular permeability factor stimulates endothelial cell growth and angiogenesis. J Clin Invest. 1989;84:1470-1478.

42. Deissler HL, Deissler H, Lang GK, Lang GE. VEGF but not P1GF disturbs the barrier of retinal endothelial cells. Exp Eye Res. 2013;115: $162-171$.

43. Deissler HL, Lang GK, Lang GE. Capacity of aflibercept to counteract VEGF-stimulated abnormal behavior of retinal microvascular endothelial cells. Exp Eye Res. 2014;122:20-31.

44. Keck PJ, Hauser SD, Krivi G, et al. Vascular permeability factor, an endothelial cell mitogen related to PDGF. Science. 1989;246:1309-1312.

45. Takahashi H, Shibuya M. The vascular endothelial growth factor (VEGF)/VEGF receptor system and its role under physiological and pathological conditions. Clin Sci (Lond). 2005;109:227-241.

46. Huang H, He J, Johnson D, et al. Deletion of placental growth factor prevents diabetic retinopathy and is associated with Akt activation and HIF1alpha-VEGF pathway inhibition. Diabetes. 2015;64:200-212.

47. Lu M, Kuroki M, Amano S, et al. Advanced glycation end products increase retinal vascular endothelial growth factor expression. J Clin Invest. 1998;101:1219-1224.

48. Park JE, Keller GA, Ferrara N. The vascular endothelial growth factor (VEGF) isoforms: differential deposition into the subepithelial extracellular matrix and bioactivity of extracellular matrix-bound VEGF. Mol Biol Cell. 1993;4:1317-1326.

49. Kim KJ, Li B, Winer J, et al. Inhibition of vascular endothelial growth factor-induced angiogenesis suppresses tumour growth in vivo. Nature. 1993;362:841-844.

50. Asano M, Yukita A, Matsumoto T, Hanatani M, Suzuki H. An antihuman VEGF monoclonal antibody, MV833, that exhibits potent anti-tumor activity in vivo. Hybridoma. 1998;17:185-190.

51. Kamiya K, Konno H, Tanaka T, et al. Antitumor effect on human gastric cancer and induction of apoptosis by vascular endothelial growth factor neutralizing antibody. Jpn J Cancer Res. 1999;90:794-800.

52. Prewett M, Huber J, Li Y, et al. Antivascular endothelial growth factor receptor (fetal liver kinase 1) monoclonal antibody inhibits tumor angiogenesis and growth of several mouse and human tumors. Cancer Res. 1999;59:5209-5218.

53. Holash J, Davis S, Papadopoulos N, et al. VEGF-Trap: a VEGF blocker with potent antitumor effects. Proc Natl Acad Sci U S A. 2002;99: 11393-11398.

54. Ozaki H, Hayashi H, Vinores SA, Moromizato Y, Campochiaro PA, Oshima K. Intravitreal sustained release of VEGF causes retinal neovascularization in rabbits and breakdown of the blood-retinal barrier in rabbits and primates. Exp Eye Res. 1997;64:505-517.

55. Tolentino MJ, McLeod DS, Taomoto M, Otsuji T, Adamis AP, Lutty GA. Pathologic features of vascular endothelial growth factor-induced retinopathy in the nonhuman primate. Am J Ophthalmol. 2002; 133:373-385.

56. Tolentino MJ, Miller JW, Gragoudas ES, et al. Intravitreous injections of vascular endothelial growth factor produce retinal ischemia and microangiopathy in an adult primate. Ophthalmology. 1996;103:1820-1828.

57. Cao J, Zhao L, Li Y, et al. A subretinal matrigel rat choroidal neovascularization (CNV) model and inhibition of CNV and associated inflammation and fibrosis by VEGF trap. Invest Ophthalmol Vis Sci. 2010; 51:6009-6017.

58. Lanzetta P, Mitchell P, Wolf S, Veritti D. Different antivascular endothelial growth factor treatments and regimens and their outcomes in neovascular age-related macular degeneration: a literature review. Br J Ophthalmol. 2013;97:1497-1507.

59. Brown DM, Heier JS, Ciulla T, et al. Primary endpoint results of a phase II study of vascular endothelial growth factor trap-eye in wet age-related macular degeneration. Ophthalmology. 2011;118: 1089-1097.

60. Regnier S, Malcolm W, Allen F, Wright J, Bezlyak V. Efficacy of antiVEGF and laser photocoagulation in the treatment of visual impairment due to diabetic macular edema: a systematic review and network metaanalysis. PLoS One. 2014;9:e102309. 
61. Basile AS, Hutmacher MM, Kowalski KG, Gandelman KY, Nickens DJ. Population pharmacokinetics of pegaptanib sodium (Macugen(R)) in patients with diabetic macular edema. Clin Ophthalmol. 2015;9:323-335.

62. Rajendram R, Fraser-Bell S, Kaines A, et al. A 2-year prospective randomized controlled trial of intravitreal bevacizumab or laser therapy (BOLT) in the management of diabetic macular edema: 24-month data: report 3. Arch Ophthalmol. 2012;130:972-979.

63. Rofagha S, Bhisitkul RB, Boyer DS, Sadda SR, Zhang K. Seven-year outcomes in ranibizumab-treated patients in ANCHOR, MARINA, and HORIZON: a multicenter cohort study (SEVEN-UP). Ophthalmology. 2013;120:2292-2299.

64. Dixon JA, Oliver SC, Olson JL, Mandava N. VEGF Trap-Eye for the treatment of neovascular age-related macular degeneration. Expert Opin Investig Drugs. 2009;18:1573-1580.

65. Rudge JS, Holash J, Hylton D, et al. VEGF Trap complex formation measures production rates of VEGF, providing a biomarker for predicting efficacious angiogenic blockade. Proc Natl Acad Sci U S A. 2007; 104:18363-18370.

66. Meyer T, Robles-Carrillo L, Robson T, et al. Bevacizumab immune complexes activate platelets and induce thrombosis in FCGR2A transgenic mice. J Thromb Haemost. 2009;7:171-181.

67. Nguyen QD, Brown DM, Marcus DM, et al. Ranibizumab for diabetic macular edema: results from 2 phase III randomized trials: RISE and RIDE. Ophthalmology. 2012;119:789-801.

68. Verheul HM, Pinedo HM. Possible molecular mechanisms involved in the toxicity of angiogenesis inhibition. Nat Rev Cancer. 2007;7: 475-485.

69. Kilickap S, Abali H, Celik I. Bevacizumab, bleeding, thrombosis, and warfarin. J Clin Oncol. 2003;21:3542.

70. Avery RL, Castellarin AA, Steinle NC, et al. Systemic pharmacokinetics following intravitreal injections of ranibizumab, bevacizumab or aflibercept in patients with neovascular AMD. Br J Ophthalmol. 2014;98: 1636-1641.
71. Roald AB, Aass HC, Moe MC. Recovery of plasma vascular endothelial growth factor concentrations during aflibercept loading phase and after the transition to bimonthly treatment for neovascular age-related macular degeneration. Br J Ophthalmol. Epub 2015.

72. Stewart MW. Pharmacokinetics, pharmacodynamics and pre-clinical characteristics of ophthalmic drugs that bind VEGF. Expert Rev Clin Pharmacol. 2014;7:167-180.

73. Stewart MW, Rosenfeld PJ. Predicted biological activity of intravitreal VEGF Trap. Br J Ophthalmol. 2008;92:667-668.

74. Christoforidis JB, Williams MM, Kothandaraman S, Kumar K, Epitropoulos FJ, Knopp MV. Pharmacokinetic properties of intravitreal I-124-aflibercept in a rabbit model using PET/CT. Curr Eye Res. 2012; 37:1171-1174.

75. Do DV, Schmidt-Erfurth U, Gonzalez VH, et al. The DA VINCI Study: phase 2 primary results of VEGF Trap-Eye in patients with diabetic macular edema. Ophthalmology. 2011;118:1819-1826.

76. Korobelnik JF, Do DV, Schmidt-Erfurth U, et al. Intravitreal aflibercept for diabetic macular edema. Ophthalmology. 2014;121:2247-2254.

77. Dhoot DS, Pieramici DJ, Nasir M, et al. Residual edema evaluation with ranibizumab $0.5 \mathrm{mg}$ and $2.0 \mathrm{mg}$ formulations for diabetic macular edema (REEF Study). Eye (Lond). 2015;29:534-541.

78. Yannuzzi NA, Klufas MA, Quach L, et al. Evaluation of compounded bevacizumab prepared for intravitreal injection. JAMA Ophthalmol.2015; 133:32-39.

79. Chang AA, Li H, Broadhead GK, et al. Intravitreal aflibercept for treatment-resistant neovascular age-related macular degeneration. Ophthalmology. 2014;121:188-192.

80. Wykoff CC, Brown DM, Maldonado ME, Croft DE. Aflibercept treatment for patients with exudative age-related macular degeneration who were incomplete responders to multiple ranibizumab injections (TURF trial). Br J Ophthalmol. 2014;98:951-955.
Drug Design, Development and Therapy

\section{Publish your work in this journal}

Drug Design, Development and Therapy is an international, peerreviewed open-access journal that spans the spectrum of drug design and development through to clinical applications. Clinical outcomes, patient safety, and programs for the development and effective, safe, and sustained use of medicines are a feature of the journal, which

\section{Dovepress}

has also been accepted for indexing on PubMed Central. The manuscript management system is completely online and includes a very quick and fair peer-review system, which is all easy to use. Visit http://www.dovepress.com/testimonials.php to read real quotes from published authors. 